\title{
FALHA POR CORROSÃO EM TUBULAÇÃO DE DESCARTE DE ÁGUA DO MAR
}

\section{FAILURE BY CORROSION IN A SEA WATER OVERBOARD LINE}

\author{
Alexandre Sponfelner Fundão ${ }^{1}$ \\ Fernando Zorzanelli da Silva ${ }^{2}$ \\ Davi Pereira Garcia ${ }^{3}$ \\ Antonio Carlos Barbosa Zancanella ${ }^{4}$ \\ Felipe Costa Novo Malheiros ${ }^{5}$ \\ Rômulo Maziero ${ }^{6}$ \\ Vinicius Silva da Cunha ${ }^{7}$
}

\begin{abstract}
Resumo: $A$ análise de falhas potenciais compreende o uso de técnicas sistemáticas que utilizam conhecimentos de engenharia para mitigar possíveis falhas, tanto do projeto quanto dos sistemas analisados, e propor ações que evitem a ocorrência dessas falhas. O problema prático de uma falha por corrosão em linha de overboard de água do mar demonstra as dificuldades que a indústria offshore enfrenta, por causa das condições extremas e a falta adequada de uma seleção de materiais para certas aplicações. Nesta pesquisa foi realizada a utilização de ferramentas de análise de falha e os conceitos para destacar a importância da melhor seleção de revestimentos internos em tubulações de aço do sistema de refrigeração com água salgada, pois quando esses revestimentos são mal selecionados acabam comprometendo a função que é a inibição dos agentes corrosivos, deixando, dessa forma, que a corrosão seja acentuada nos pontos onde o revestimento falha. Os resultados desta pesquisa contribuem para auxiliar a indústria na seleção e aplicação de revestimentos em tubulações de aço dos sistemas de refrigeração com água salgada.

Palavras-chave: análise de falha; FMEA; FTA.
\end{abstract}

Abstract: Potential failure analysis comprises the use of systematic techniques that use engineering knowledge to mitigate possible failures of both the project and the systems analyzed, and which propose actions to prevent the occurrence of these failures. The practical problem of failure by corrosion in a sea water overboard line demonstrates the difficulties faced by the offshore industry, because of the extreme conditions and lack of proper selection of materials for certain applications. This research was conducted using failure analysis tools and concepts to highlight the importance of the best selection of internal coatings on steel pipes of the cooling system with sea water, since when these coatings are poorly selected, they compromise the function, which is the inhibition of corrosive agents, thereby allowing the corrosion to be pronounced at points where the coating fails. The results of this research contribute to assist the industry in the selection and application of coatings on steel pipes of refrigeration systems with salt water.

Keywords: failure analysis; FMEA; FTA.

\footnotetext{
${ }^{1}$ Instituto Federal do Espírito Santo - IFES (Campus São Mateus), Brasil. E-mail: alexandrefundao@hotmail.com.

2 Instituto Federal do Espírito Santo - IFES (Campus São Mateus), Brasil. E-mail: fernandozorzanelli@gmail.com.

${ }^{3}$ Instituto Federal do Espírito Santo - IFES (Campus São Mateus), Brasil. E-mail: davi.garcia@ifes.edu.br

${ }^{4}$ Instituto Federal do Espírito Santo - IFES (Campus São Mateus), Brasil. E-mail: antonio.zancanella@ifes.edu.br.

${ }^{5}$ Instituto Federal do Espírito Santo - IFES (Campus São Mateus), Brasil. E-mail: felipe.malheiros@ifes.edu.br.

6 Instituto Federal do Espírito Santo - IFES (Campus São Mateus), Brasil. E-mail: maziero.ifes@gmail.com.

${ }^{7}$ Instituto Federal do Espírito Santo - IFES (Campus São Mateus), Brasil. E-mail: vinicius.cunha@ifes.edu.br.
} 


\section{INTRODUÇÂO}

As atividades operacionais relacionadas à produção de petróleo envolve prospecção em ambientes cada vez mais agressivos, sejam pela alta pressão, altas temperaturas ou o próprio ambiente marinho. Nessas condições, a corrosão continua a ser o maior obstáculo operacional para o sucesso na produção de hidrocarbonetos e o controle e gerenciamento são necessários para a segurança das operações e na diminuição dos custos de produção.

A corrosão-erosão acelera a corrosão por dispersão dos mecanismos que protegem os metais em contato estático ou em movimento lento, em um ambiente aquoso. Como o nome implica, um aspecto do efeito é a retirada de metal e óxidos que estão na superfície do material, que interfere na formação da camada passiva, muitas vezes responsáveis pela proteção contra corrosão (MCCAFFERTY, 2010). A indústria prefere a utilização do aço carbono e de baixa liga, os quais estão disponíveis em grandes volumes e satisfazem os requerimentos mecânicos, estruturais, de fabricação e de custos. A tecnologia desses aços está bem desenvolvida, representando uma escolha de custo-benefício para muitas aplicações. Entretanto, possuem baixo desempenho em relação à corrosão-erosão.

As falhas ocasionadas pela corrosão interna em tubulações de aço com revestimento de polietileno são difíceis de serem identificadas. Se o líquido em movimento transportar partículas sólidas em suspensão, o efeito de retirada do material é ainda maior. O movimento relativo também tende a varrer a camada limite do líquido presente na interface metal/líquido. Isso estimula ainda mais a corrosão por meio da dispersão de polarização de concentração, especialmente para a reação de redução de oxigênio (MCCAFFERTY, 2010). Devido à impossibilidade de uma manutenção preventiva, esses tipos de incidentes afetam diretamente na segurança e produção de unidades de exploração de petróleo.

O revestimento de polietileno é uma das alternativas para a minimização do efeito da corrosão por apresentar elevada resistência química à água do mar e à abrasão. Uma desvantagem, no entanto, é que quando ocorre a permeação de água pelo polímero, atingindo a superfície do aço carbono, o óxido formado acaba por destacar grandes áreas do revestimento.

O trabalho teve como objetivo apresentar análises de falha sobre a ótica da análise dos modos de falhas e efeitos (FMEA) e análise da árvore de falha (FTA), assim como, hipóteses que podem promover a falha na tubulação.

\section{MATERIAIS E MÉTODOS}

Em uma unidade offshore foi constatada a ocorrência de falha na linha de descarte 
de água do mar, mostrada na Figura 1, causando inundação na praça de máquinas. Essa linha é do sistema de refrigeração dos compressores, fabricada em aço carbono com revestimento interno em polietileno.

Figura 1. Local da falha por corrosão.

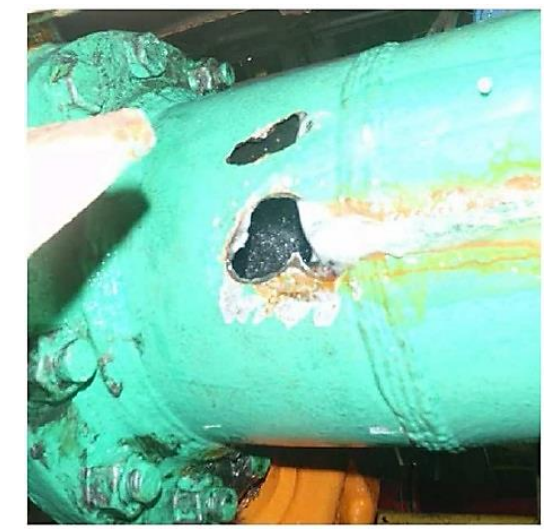

Fonte: Autores.

Foi observada uma grande área interna da tubulação sem o revestimento de polietileno, apresentada na Figura 2.

Figura 2. Falha no revestimento de polietileno.

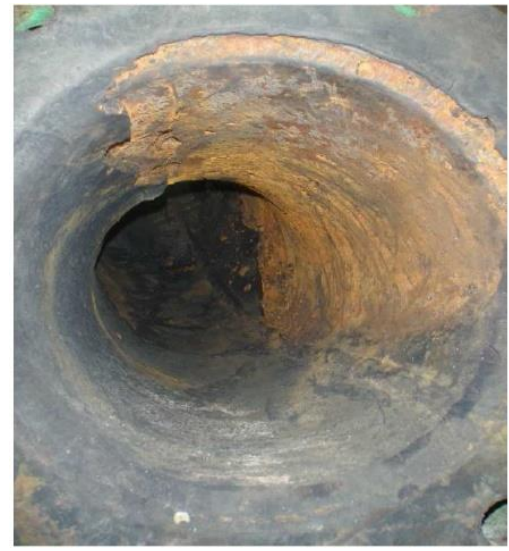

Fonte: Autores.

Foi realizada uma análise de falhas segundo metodologia FTA e FMEA, que são técnicas frequentemente utilizadas em conjunto, dado que são normalmente complementares. Enquanto a FTA é mais visual, a FMEA permite detalhar os eventos a partir da função de cada um dos itens do sistema, e os respectivos modos de falha e efeito para o produto em análise ou para parte dele em que serão expostos os sistemas, eventos e sub eventos causadores da falha na tubulação. 


\section{RESULTADOS E DISCUSSÃO}

\subsection{Análise de falhas}

Para levantar hipóteses sobre possíveis causas das falhas utilizou-se FTA e FMEA como ferramentas de análise, sendo a FTA uma abordagem top-down, ou seja, a análise parte de um evento/efeito indesejado (evento de topo) e investiga associação lógica das causas que resulta no evento/efeito indesejado, já FMEA é uma abordagem bottom-up, ou seja, a análise parte de um modo de falha e investiga os efeitos que a ocorrência pode gerar no sistema. O Quadro 1 e a Figura 3 exemplifica a relação entre FTA, cuja análise segue na direção das causas, e da FMEA, cuja análise segue na direção dos efeitos, utilizando a árvore de falha como ferramenta de mitigação, encontrou-se o causador da falha e atribuíram-se possíveis soluções para o ocorrido.

Quadro 1. FTA como elemento complementar a FMEA.

\begin{tabular}{|c|c|c|c|c|c|}
\hline \multicolumn{6}{|c|}{ Sistema: Sistema de água de refrigeração } \\
\hline \multicolumn{6}{|c|}{ Subsistema analisado: Linha de descarga para mar (linha de overboard) } \\
\hline $\begin{array}{l}\text { Componente/ } \\
\text { função }\end{array}$ & \begin{tabular}{|l|} 
Falha \\
funcional
\end{tabular} & Modo de falha & \multicolumn{3}{|c|}{ Efeito } \\
\hline \multirow{3}{*}{$\begin{array}{l}\text { Motobombal } \\
\text { bombear água }\end{array}$} & $\begin{array}{l}\text { Não obedece } \\
\text { comando de } \\
\text { partida } \\
\end{array}$ & \multirow{2}{*}{$\begin{array}{l}\text { Quebra por } \\
\text { desgaste } \\
\text { excessivo ou } \\
\text { engripamento }\end{array}$} & Local & Sistema & Planta \\
\hline & $\begin{array}{l}\text { Não obedece } \\
\text { comando de } \\
\text { parar }\end{array}$ & & \multirow{2}{*}{$\begin{array}{l}\text { Pequeno } \\
\text { vazamentol } \\
\text { sobreaquecimen } \\
\text { to }\end{array}$} & \multirow{2}{*}{$\begin{array}{l}\text { Risco iminente de } \\
\text { indisponibilidade da } \\
\text { bomba }\end{array}$} & \multirow[t]{2}{*}{ 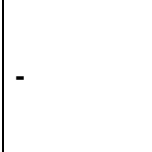 } \\
\hline & Baixa pressão & \begin{tabular}{|l|}
$\begin{array}{l}\text { Vazamento no } \\
\text { selo }\end{array}$ \\
\end{tabular} & & & \\
\hline \multirow{2}{*}{$\begin{array}{l}\text { Pressostatos } \\
\text { de parada das } \\
\text { motobombas/ } \\
\text { indicar } \\
\text { pressões } \\
\text { baixa/ alta }\end{array}$} & $\begin{array}{l}\text { Não parar a } \\
\text { motobomba }\end{array}$ & \begin{tabular}{|l|} 
Falha no \\
instrumento
\end{tabular} & \multirow[b]{2}{*}{$\begin{array}{l}\text { Abertura da } \\
\text { válvula de alívio }\end{array}$} & \multirow[b]{2}{*}{$\begin{array}{l}\text { Refrigeração } \\
\text { ineficiente }\end{array}$} & \multirow[b]{2}{*}{ - } \\
\hline & $\begin{array}{l}\text { Parar } \\
\text { indevidamente }\end{array}$ & \begin{tabular}{|l|} 
Ajuste \\
incorreto/ \\
operação \\
indevida \\
\end{tabular} & & & \\
\hline \multirow{3}{*}{$\begin{array}{l}\text { Tubulações/ } \\
\text { conduzir água }\end{array}$} & \multirow{3}{*}{$\begin{array}{l}\text { Não conduzir } \\
\text { a água } \\
\text { corretamente }\end{array}$} & CORROSÃO & \multirow{3}{*}{$\begin{array}{l}\text { Risco de } \\
\text { acidente e } \\
\text { alagamento } \\
\text { progressivo }\end{array}$} & \multirow{3}{*}{$\begin{array}{l}\text { Parada imediata do } \\
\text { sistema }\end{array}$} & \multirow{3}{*}{$\begin{array}{l}\text { Preparaçã } \\
\text { o para } \\
\text { parada da } \\
\text { planta/ } \\
\text { abandono }\end{array}$} \\
\hline & & \begin{tabular}{|l|}
$\begin{array}{l}\text { Impacto } \\
\text { externo }\end{array}$ \\
\end{tabular} & & & \\
\hline & & Obstrução & & & \\
\hline \multirow{2}{*}{$\begin{array}{l}\text { Válvula de } \\
\text { alívio/ limitar a } \\
\text { pressão }\end{array}$} & \begin{tabular}{|l|}
$\begin{array}{l}\text { Não aliviar a } \\
\text { pressão }\end{array}$ \\
\end{tabular} & Emperramento & \multirow{2}{*}{$\begin{array}{l}\text { Rompimento da } \\
\text { tubulação/ risco } \\
\text { de acidente }\end{array}$} & \multirow{2}{*}{$\begin{array}{l}\text { Falha da } \\
\text { motobombal } \\
\text { sobreaquecimento }\end{array}$} & \multirow[b]{2}{*}{ - } \\
\hline & $\begin{array}{l}\text { Atuar abaixo } \\
\text { da pressão de } \\
\text { ajuste }\end{array}$ & $\begin{array}{l}\text { Ajuste } \\
\text { indevido }\end{array}$ & & & \\
\hline
\end{tabular}

Fonte: Autores.

$\mathrm{Na}$ abordagem do FMEA híbrido, utiliza-se uma coluna para a falha funcional, outra para o modo de falha, que é a causa imediata da falha funcional, e outra para as causas imediata, intermediária ou, eventualmente, raiz. Dessa forma, contempla a nomenclatura de ambas as normas RCM (SAE JA1011 e JA1012) e SAE J1739 (SAE 2002b) (DIAS, 2011). A partir da definição de FTA, seguiu-se na direção das causas, ou seja, mostraram-se as possíveis causas relacionadas à falha sem levar em consideração os efeitos. 
Figura 3. FTA como elemento complementar a FMEA.

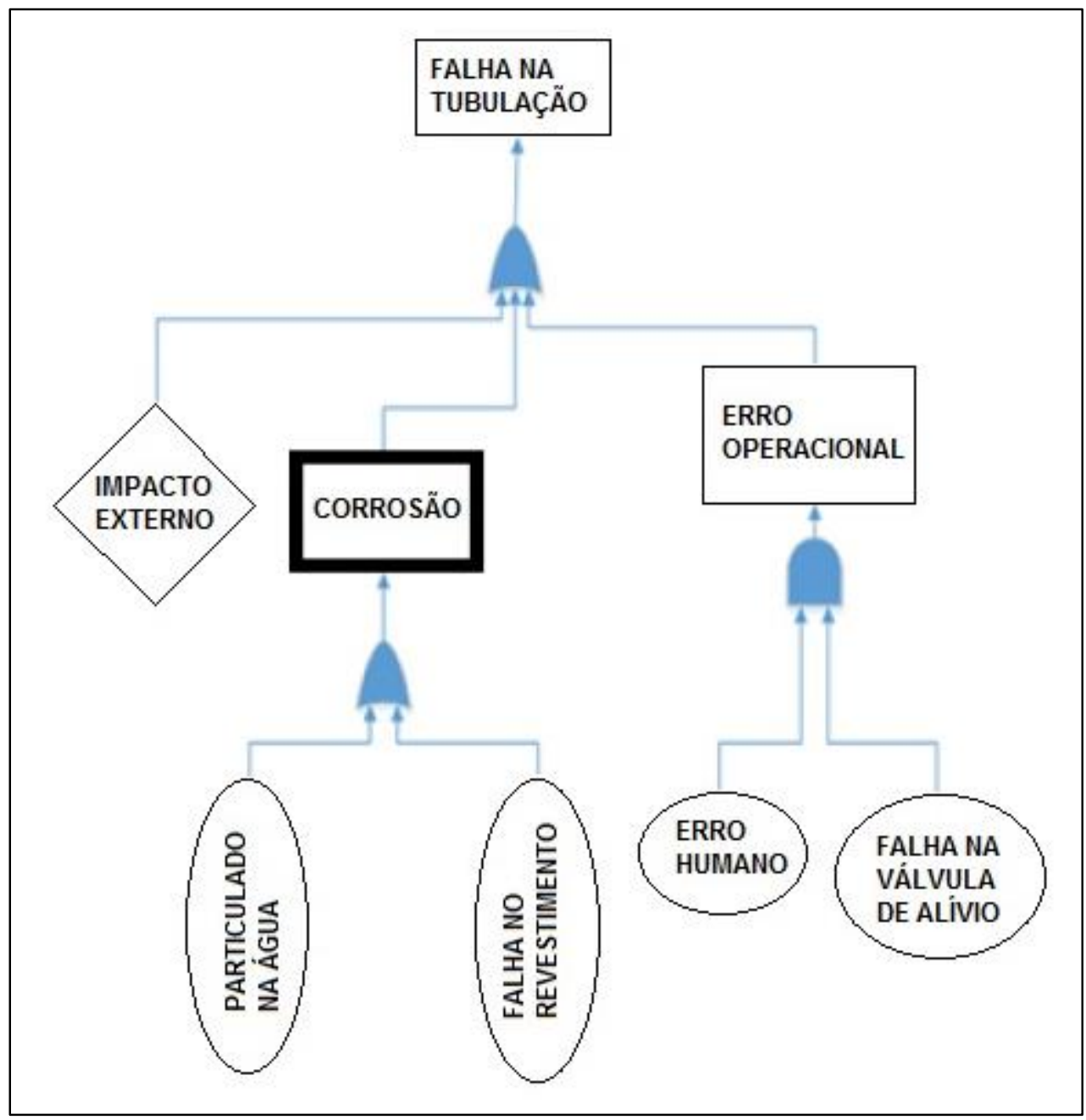

Fonte: Autores.

Por meio da árvore de falha, obtiveram-se três sub eventos topo ou intermediários que levaram a três hipóteses: erro operacional, impacto externo e corrosão. Independentemente da abordagem, a FMEA e a FTA podem ser utilizadas de maneira complementar para facilitar a análise, detalhar pontos de interesse e/ou validar o conhecimento (HELMAN; ANDERY, 1995; SCAPIN, 1999).

A FTA concentra-se em um único efeito indesejado ou falha de cada vez para, então, estabelecer o relacionamento lógico de todas as causas básicas que irão resultar no evento de topo, característica não contemplada pela FMEA. Vale destacar que é possível desdobrar, por meio da árvore de falha, qualquer evento ao longo de uma cadeia causal presente na FMEA, e isso significa que um evento de topo ou sub evento topo pode ser um efeito indesejado, um modo de falha de um componente, ou até mesmo, uma causa raiz que se deseja mitigar. (DIAS, 2011).

\subsection{Primeira hipótese: impacto externo}


Hipótese descartada após verificação da tubulação, Figura 4, que apresentava mais de um furo amorfo, descaracterizando um possível impacto. Além disso, não havia, no local, qualquer tipo de material solto, que, com o impacto, poderia provocar furos na linha.

\section{Figura 4. Furo na linha de overboard.}

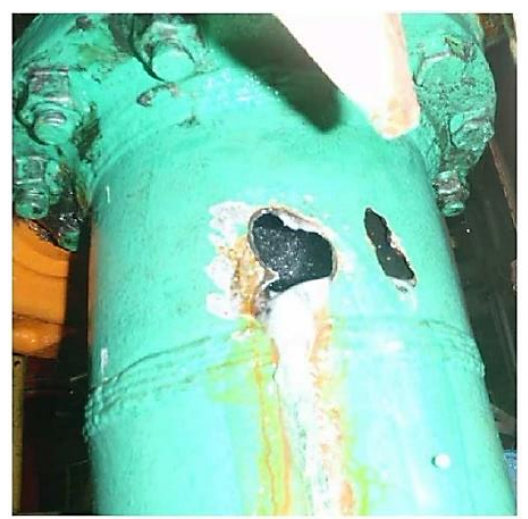

Fonte: Autores.

\subsection{Segunda hipótese: erro operacional}

Essa possibilidade foi descartada após a análise da terceira hipótese, uma vez que se considerar que a tubulação já se encontrava com um estado de corrosão avançada, o aumento da pressão na linha provocaria a falha antes de atingir o valor necessário para abrir a válvula de alívio, ou seja, a pressão necessária para abrir a válvula de alívio seria maior que a existente na linha durante a ocorrência da falha.

\subsection{Terceira hipótese: falha do liner de polietileno}

A presença de particulado na água poderia ter ocasionado o desgaste do revestimento. Devido à velocidade de escoamento, o impacto desses materiais acentuaria o processo de erosão do revestimento de polietileno, deixando a tubulação exposta à água salgada. Após esse processo, o aço carbono ficaria exposto a esse fluxo de água do mar com particulado, caracterizando um processo de corrosão-erosão na tubulação após a falha do revestimento. A presença de particulado sólido foi descartada após a constatação da integridade do filtro de sucção da bomba booster, como representada na Figura 5, que esquematiza a linha de refrigeração da unidade de exploração, descaracterizando o processo de corrosão-erosão por causa da inexistência de particulado. 
Figura 5. Esquemático captação/descarga de água do mar.

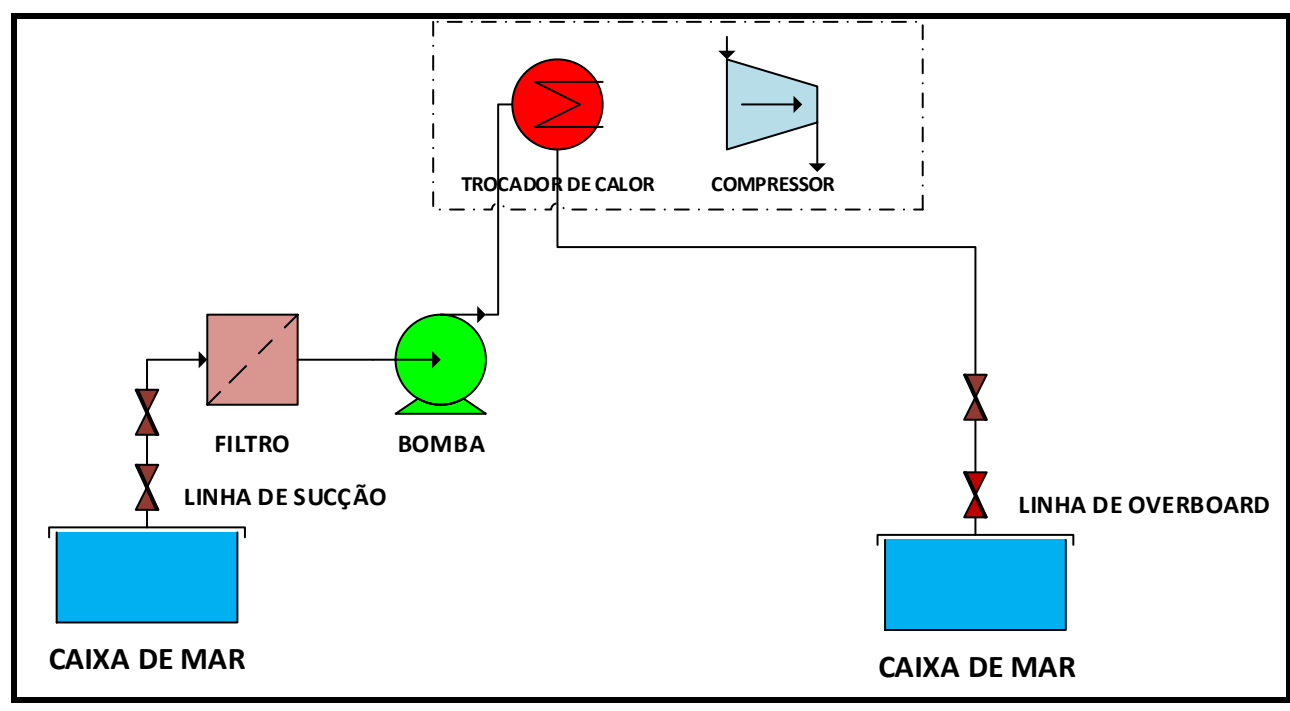

Fonte: Autores.

Segundo Bayer (2013), os principais requisitos de um revestimento são: baixa permeabilidade, resistência química ao meio agressivo, dilatação térmica compatível com o substrato, propriedades físicas adequadas aos abusos que receberá por abrasão, tráfego, impacto, flexão, entre outros. As características são: monolítico (sem emendas), remota ocorrência de trincas ou fissuras, não permite infiltrações, fácil e rápida aplicação, aceita reparos localizados, equipamentos de suporte simples e baixo custo. O processo de falha do liner de polietileno não foi totalmente descartado, partindo do princípio que a corrosão não aconteceria sem a falha do revestimento de polietileno, foi suposto que houve permeação do polietileno.

Como mencionado anteriormente, o revestimento de polietileno é capaz de proporcionar excelente proteção contra corrosão, o polietileno possibilita: alta resistência a impacto e torção, nas condições de serviço da tubulação estudada, além de uma boa resistência química em condições de água de injeção doce ou salgada desaerada, água de injeção salgada, aerada e água salgada aerada. Porém, a partir do momento em que o polietileno sofre a permeação, ocorre a formação de uma pilha de concentração, devido à diferença de concentração do meio que permeou o revestimento e o interior da tubulação, fazendo com que haja um processo primário de corrosão. $A$ formação do óxido causado por essa diferença de concentração faz com que o revestimento se desprenda, deixando a tubulação de aço carbono desprotegida do revestimento e, consequentemente, exposta ao escoamento.

Dentre as possíveis causas para essa permeação do revestimento, pode-se citar a falta de aderência no material base, algum impacto que perfurou o liner durante a instalação da tubulação ou falha no acabamento do revestimento entre os flanges da tubulação. Qualquer um dos motivos expostos anteriormente causaria permeação do revestimento, provocando o mecanismo de seu desprendimento, como explicado. Além 
do desplacamento do revestimento de polietileno, ocorreu, também, um segundo mecanismo de corrosão quando a tubulação ficou exposta ao escoamento da água do mar em uma zona de turbulência (cotovelo), essa forma de corrosão é chamada de corrosão acelerada pelo fluxo.

\section{CONCLUSÃO}

A terceira hipótese, falha do revestimento de polietileno, devido às características do revestimento e ineficiência, fez com que, a partir do momento em que ocorreu a permeação da água no revestimento, a funcionalidade na tubulação foi perdida, iniciando diferentes mecanismos de corrosão.

Como alternativa para possíveis substitutos e/ou solução para revestimentos internos em tubulações de água salgada de sistema de refrigeração, propõem-se materiais como a resina epóxi.

\section{REFERÊNCIAS}

BAYER, R. F. Critérios para especificação de revestimentos anticorrosivos. 2001. Disponível em: <http://www.narus.com.br/trabalhos_artigos.aspx?id_categ=19>. Acesso em: 24 mar. 2013.

DIAS, Acires et al. Metodologia para análise de risco: mitigação de perda de SF6 em disjuntores. Florianópolis: Studio S, 2011. 304 p.

HELMAN, Horacio; ANDERY, Paulo Roberto Pereira. Análise de falhas: aplicação dos métodos FMEA e FTA. Belo Horizonte: UFMG, Escola de Engenharia, 1995. 156 p.

MCCAFFERTY, Edward. Mechanically Assisted Corrosion. In: Introduction to Corrosion Science. New York: Springer, 2010. p. 315-356.

SCAPIN, C. A. Análise sistêmica de falhas. Belo Horizonte: Editora de Desenvolvimento Gerencial, 1999. 132p. 